\title{
AS CORES DO BRANCO
}

\section{Cristina Monteiro de Castro Pereira}

Haroldo de Campos, um de nossos poetas mais criativos e inovadores, foi também um tradutor de peso, responsável pela introdução, em língua portuguesa, de obras de extrema importância em qualquer meio literário. Por seu "intransmédio", uma espécie de intermédio transformador, os leitores brasileiros tiveram acesso a Homero, Dante, Pound, Maiakóvski, entre tantos outros poetas - alguns mais, outros menos conhecidos, mas todos de grande relevância para os amantes das Letras.

Poesia, tradução e crítica. A tríade rege a trajetória de Haroldo, sempre perseguindo uma meta: a invenção. Impossível não notar a afinidade com as idéias de Ezra Pound. Para este, a poesia e a tradução são modalidades da crítica: crítica pela tradução e crítica pela poesia. A invenção, o valor maior.

Na obra de Haroldo de Campos, os três elementos estão sempre em movimento, remetendo-se uns aos outros, em uma coreografia guiada pela invenção. A tradução é criativa, é uma "transcriação", como dizia o poeta.

Ao contrário do percurso da tradução mais tradicional, que prioriza o sentido do texto em detrimento da forma, Haroldo busca recriar a composição estética do poema, fazendo-a funcional em português. O sentido não é, de modo algum, desprezado, mas, quando precisa escolher entre um efeito estético, capaz de recriar aquele provocado pelo original, e o sentido mais fiel, sem dúvida, fica com a primeira opção. Segue a meta da invenção, procura sempre fazer com que prevaleça a dança entre som, sentido e imagem. O objetivo é recriar para resgatar, em sua língua, não o original, mas sua informação estética. E fazer, da tradução, um novo original.

A escolha dos textos a serem traduzidos, ou transcriados, a partir de um critério teórico já é uma ação crítica, que determina um paideuma, ou seja, um grupo de obras que é distinguido por Haroldo como relevante. Seu interesse era traduzir textos densos em efeitos (sonoros, visuais e / ou de "jogos verbais") capazes de desestabilizar a leitura fácil por sua inovação estética. Desse modo, a tradução pode produzir uma leitura 
crítica, para estudantes e interessados, permitindo a comparação dos "mecanismos e engrenagens mais íntimos" da obra artística.

Poesia e "prosapoema" - como o Finnegans Wake, densos, concentrados, complexos; e porosos, articuláveis, cambiantes - foram os focos deste "transcriador", para quem, quanto mais desafiador é o texto, maior o potencial da tradução.

O livro Transblanco (1986) surgiu por uma sugestão de Haroldo de Campos a seu amigo e missivista, o poeta mexicano Octavio Paz. Uma amizade que se desenvolveu através de cartas, enraizada em interesses comuns: poesia, tradução, crítica. A certa altura, Haroldo revelou o seu desejo de traduzir "Blanco", um poema longo de Paz, cujo modo de composição se aproxima das experiências "concretas" do poeta paulista. Octavio Paz se interessou pelo projeto e se prontificou a discutir os pontos mais capciosos que poderiam surgir durante a tradução. Assim foi feito, por meio de uma significante correspondência. Ambos concordaram em juntar as cartas ao poema para compor um livro, o que também permitiria o acesso dos leitores ao processo da tradução.

A leitura de Transblanco é muito interessante: temos as duas versões completas do poema, em espanhol e em português. Juntam-se a elas algumas notas e comentários de Octavio Paz, indicando as chaves estruturais do poema e caminhos para suas possíveis leituras. A transcrição de sua fala, realizada pela Rádio USP, a respeito de "Blanco" começa com uma proposta muito cara aos, então, "poetas concretos": "Este poema é uma tentativa no sentido de transformar o tempo em espaço".2.

Como nos poemas concretos de Haroldo (e dos demais membros do grupo da poesia concreta), "Blanco" não se desenrola apenas no tempo linear, tradicionalmente designado à poesia. Para fruir de sua multiplicidade de sentidos, é preciso lê-lo também como um quadro, que se revela em uma configuração espacial, transformando o tempo em espaço.

O poema é regido, também segundo Paz, pela figura oriental do mandala, em que se representam os quatro pontos cardeais, os quatro elementos da natureza (fogo, água, terra e ar) e as quatro faculdades da filosofia (a sensação, a percepção, a imaginação e o entendimento). Divide-se em colunas — uma, duas ou três, que podem ser lidas continuamente ou separadamente. Mulher e linguagem se entrelaçam: do branco pré-nascimento, passando pelo desenvolvimento erótico que os envolve, até

\footnotetext{
${ }^{1}$ CAMPOS: 1992, 46.

${ }^{2}$ PAZ O., CAMPOS, H., 1994, 87.
} 
chegar ao alvo do poeta, ao orgasmo, ao poema, ao fim. Aquém, o branco do pré-início, o silêncio; além da linguagem, o alvo e, novamente, o silêncio. No espaço entre o branco e o branco, o poema, as peripécias da linguagem em seu erótico percurso de vida, que atravessa os grupos de quatro elementos designados acima.

O título já foi um dos problemas para Haroldo, conforme escreve na carta a Octavio Paz:

(Desde logo, há um problema com o título: em português, branco não tem o significado substantivo de 'objeto situado longe, para exercícios de tiro e pontaria'; a palavra correspondente é alvo, que, todavia, não é tão 'forte' como branco — por ser algo rebuscada - em sua acepção adjetiva de cor... Creio que convém adotar "Branco" no título, sopesados todos os aspectos semânticos e estéticos da questão). ${ }^{3}$

Sem dúvida, a palavra "alvo" apresenta, como Blanco, as duas acepções: a da cor e a de meta a ser alcançada. Mas a "brancura do branco", que contém todas as cores em potência, que é o silêncio das cores, seu "pré" e seu "des" aparecimento, não é alcançada pelo "alvo". E é justamente a ideia de destacar-se do branco e formar, aos poucos, cores-palavras que este percurso da linguagem propõe. As palavras nascem com as cores, que iluminam os quatro elementos e as quatro faculdades. O poema começa com o silêncio do branco, passa pelo amarelo do fogo e pela sensação, início do erotismo. Em seguida, o vermelho, líquido, água-fogo-sangue: entramos na percepção. Passamos para a cor verde, o elemento terra e a imaginação, até chegar ao azul, ao ar e ao entendimento. E voltamos / chegamos ao alvo: o branco.

Ao receber a tradução de Haroldo, Octavio Paz tece novos comentários, marcando alguns trechos sobre os quais desejava discutir. A impressão de Paz sobre a transcriação de seu poema foi das melhores. Cabe aqui transcrevê-la para sublinhar a visão de um poeta sobre a recriação de sua obra em outra língua e destacar seus principais pontos de interesse em relação à tradução.

Li e reli sua admirável tradução. Estou de fato comovido. Não só é muito fiel mas, ainda, por vezes, o texto português é melhor e mais conciso do que o espanhol. Você conseguiu recriar não só o sentido do poema, mas também o movimento. Quanto ao ritmo, que é o mais difícil de traduzir, o grande obstáculo com que nos defrontamos nós todos, tradutores de poesia: até onde posso julgar, parece-me que você conseguiu reproduzir a polimetria do original. Também é notável — outra proeza - que você tenha encontrado as equivalências das aliterações, paronomásias e outros ecos verbais. ${ }^{4}$

\footnotetext{
${ }^{3}$ Idem, 117.

${ }^{4}$ Idem, 121.
} 
Os dois poetas se afinam também em relação à teoria da tradução. Como Pound, perseguem a recriação do poema, "make it new", torná-lo um novo original, com força capaz de dialogar com o texto de partida, enriquecendo um ao outro. Haroldo de Campos designa o tipo de tradução que produz como "tradução criativa", uma prática "paramórfica" que, "ao lado de", acentua o processo de diferenciação e de diálogo que a envolve no encontro com o poema. Desse modo, algumas vezes, a solução da tradução pode ser mais eficiente do que a do original. Como, por exemplo, em uma das questões discutidas pelos poetas a respeito do trecho a seguir (a coluna da direita aparece, no poema de Paz, em vermelho):

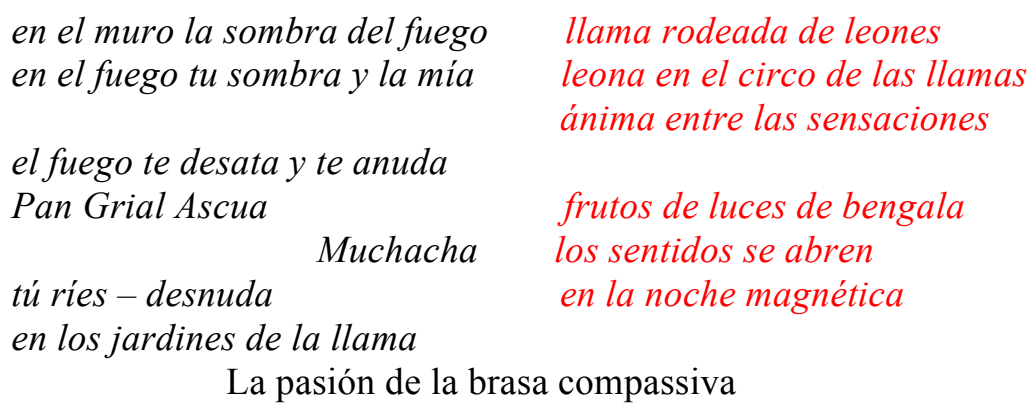

no muro a sombra do fogo

chama rodeada de leões

no fogo tua e minhas sombras leoa no círculo das chamas alma animando sensações

o fogo te ata e desata

Pão Graal Áscua

Mulher

frutos de fogos-de-bengala

os sentidos se exabrem

teu riso - nua na noite magnética

entre os jardins da chama

Paixão de brasa compassiva

No terceiro verso da coluna à direita (linha 46), Haroldo contou com a aprovação e o agradecimento de Paz: “'Alma animando sensações” está cheio de ressonâncias animistas, que é o que eu queria. Obrigado.”.

A informação estética do original é recriada em português, ainda que, para isso, o tradutor tenha que se equilibrar em um difícil jogo entre criação e literalidade. Sobre o segundo verso da direita, explica Haroldo de Campos:

... quando em lugar de "leona en el circo de las llamas", escrevo "leoa no circulo das chamas', não se imagine que, desatento, "tresli", dando "círculo" por "circo"; subentenda-se, antes, que me deixei guiar deliberadamente por uma sugestão prosódica (um verso de nove sílabas, com a tônica na quinta, mimando a música do original), reforçada pela vinculação etimológica entre ambas as palavras e, ainda, pela relação 
sinedóquica que se estabelece (e que a imagem de O. Paz insinua) entre o "círculo em chamas" usado pelos domadores em espetáculos de feras e o próprio recinto circular da arena. $^{5}$

Em outra passagem, Paz chama a atenção de Haroldo, que havia traduzido "Pan Grial Ascua" por "Pão Graal Centelha", para a possibilidade de manter a palavra "áscua", pois não via em "centelha" a potencialidade necessária para substituí-la. O tradutor justifica a sua escolha, mas concorda com o poeta mexicano:

\begin{abstract}
Vou mudar. Posso manter áscua em port. No meu idioma, áscua tem duas acepções: a) centelha e b) brasa, carvão ardente (a acepção "b" é mais obsoleta, mas existe ainda: "olhos que brilham como áscuas", "as áscuas da dor") Assim:

Pão Graal Áscua.

$\mathrm{Eu}$ havia utilizado centelha em função do jogo fônico que faz com mulher (centELHa/muLHEr), réplica ao seu ÁscUA/mUchAchA. Mas me dou conta de que o jogo funciona com AscUa e nUA em minha tradução, um pouco mais adiante. ${ }^{6}$
\end{abstract}

Logo em seguida, Haroldo responde a mais uma dúvida de Paz: seria "mulher" a melhor tradução para "muchacha"? Sim, confirma, até porque as outras opções que se aproximariam do vocábulo, "jovem" e "moça", não contêm a força semântico-erótica de "muchacha" e, "mulher", por ser uma palavra mais abrangente em português, pode tomar o seu lugar.

Mais à frente no poema (linhas 90-91), Haroldo contorce o português, criando uma nova palavra, para conseguir o efeito desejado, próximo ao texto em espanhol.

\footnotetext{
Mientras los otros trabajan

Es pulir huesos,

Silencios

Aguzar

Hasta la transparencia,

Hasta la ondulación,

Hasta el agua:

El cabrilleo,
}

Hablar

Falar

Enquanto os outros trabalham

É polir ossos,

Silêncios

$$
\text { Aguçar }
$$

À ondulação,

\footnotetext{
${ }^{5}$ Idem, 93.

${ }^{6}$ Idem, 124
} 
Até à água: $\quad$ Ao corusqueio,

Sobre sua tradução, explica a Paz:

Inventei em port. corusqueio (de coruscar, brilhar como um vidro ao sol, ou como a água quando produz cintilações numa cascata). Antes de mais nada, é uma transposição fonicônica de

\section{CA BRI LLE O \\ CO RUS QUEI O,}

uma parafonia (Há em port. encapelar-se — “o encapelar-se", para traduzir cabrilleo, porém não resultaria suficientemente expressivo.) ${ }^{7}$

Transgredir os limites de sua própria língua para aproximá-la do potencial estético do texto original e, com isso, construir um novo original. Como Hölderlin, condenado por seus contemporâneos por sua vermelhidão, por sua afiada literalidade, que expôs, para a posteridade, oinopa ponton, o mar cor de vinho pré-tempestade da tradição homérica, na fala de Ismênia. Schelling, Goethe, e Schiller se juntavam a Johann Heinrich Voss, tradutor tradicional da Ilíada e da Odisséia em língua alemã, para ridicularizar aquele que, nos dias de hoje, é considerado quase um visionário da tradução atual.

Hölderlin, em sua tradução da Antígona de Sófocles, escolheu traduzir uma frase da personagem Ismênia de modo radical e literal, na intenção de resgatar a metáfora original e, com isso, se afastando de uma construção mais "alemã”, capaz de clarificar o sentido. O verbo kalkháino, "ter a cor escura da púrpura", tem também o sentido de “estar sombrio, estar mergulhado em reflexões, meditar profundamente sobre qualquer

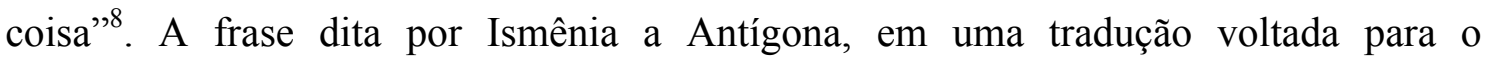
esclarecimento do sentido, seria algo como "alguma coisa te atormenta". Na tradução de Hölderlin e na de Haroldo, o sombrio e a cor vermelha, anunciadora de maus presságios desde os tempos homéricos, se unem na tragédia de Sófocles: "Du scheinst ein rotes Wort zu färben / Tua fala se turva de vermelho". Contrastando com a tradução que se apóia no sentido, para buscar o modo mais fácil de promover a compreensão, Hölderlin queria transportar o leitor para o mundo grego ao ressaltar a postura de Antígona,

\footnotetext{
${ }^{7}$ Idem, 128.

${ }^{8}$ CAMPOS, H., 1977, 99.
} 
símbolo das tradições de seu povo, ainda que, para isso, tivesse que o inserir no meio do caos, si(a)ngrando pelos mares revoltos do texto, sem a certeza de um porto seguro.

Sobre a tradução de Hölderlin, Walter Benjamin ressaltou, no ensaio "A Tarefa do Tradutor" (1923), seu sucesso em alcançar uma harmonia tão profunda entre as línguas, em que o sentido é apenas "tangido" pela linguagem. A linguagem, nesse tipo de tradução, não é serva do sentido. Ao contrário, é sua formulação, sua configuração no texto que, tangenciando o significado, é capaz de se transformar na expressão mais viva e / do original.

Vale lembrar, a respeito das idéias sobre tradução de Benjamin, a referência à "lingua pura", original (Ursprache), a língua comum entre Deus e os homens, presente nas linhas do Velho Testamento. Essa língua teria existido até que estes, acometidos pela hybris, pela impertinência desmedida, construíram uma torre gigantesca, com o propósito de alcançar o céu, território proibido, morada de Deus. Ofendido, o Todo Poderoso lança sua vingança: destrói a torre de Babel e fragmenta a linguagem, disseminando línguas, estrangeiras umas às outras, e dificultando o entendimento entre os homens.

A este episódio bíblico, se sobrepõe a imagem de Deus como linguagem e como origem, imagem essencialista que não se sustenta no universo de Haroldo de Campos. Mas a idéia de uma aproximação das línguas pela tradução, no sentido de alargar as possibilidades de efeitos concretos e de estender a potência da escrita, é bem-vinda. A "língua pura" se torna uma metáfora para a experiência estética, o indizível, impossível de ser resgatado, mas capaz de ser recriado.

A tradução do sentido de um texto pode ser muito eficiente para a compreensão entre diferentes povos, mas jamais seria capaz de tocar a "língua pura", insight de "entrentendimentos" mais profundos. A melancolia se instaura: impossibilidade de recuperar algo perdido. Já a tradução criativa, mais propensa à mesma hybris responsável pela perda da "língua pura", aposta na transgressão, no transpasse dos limites de sua própria língua para aproximar-se do efeito do original (texto e "língua"). A hybris desfez. A hybris é capaz de refazer? A hybris é capaz de recriar uma configuração, como diria Haroldo, paramórfica, capaz de dialogar com o original, iluminando, a partir de suas diferenças, parte da plenitude da "língua adâmica". Voltando a Benjamin, a potência não está no que é "dito" (das Gemeinte), mas no “modo de dizer" (Art des Meinens). 
O sentido, apenas tangenciado, se transforma em informação estética, em estruturas "concretas", sonoras, visuais e verbais. Ele é, ao mesmo tempo, disseminado e concentrado em uma montagem que permite ao tradutor e a seu leitor passar por uma experiência estética, experiência esta que, segundo Immanuel Kant, é universal, e que, poderíamos dizer, se comporta paramorficamente à de tocar a língua das línguas, a "língua pura".

Para "transcriar" o poema "Blanco", Haroldo de Campos se utilizou do confronto com outras traduções: uma francesa e duas inglesas, na procura dos fragmentos mais expressivos para recriar, em português, a informação estética do texto em espanhol (ou, metaforicamente, a "língua original").

Ao ser questionado por Paz sobre sua escolha de utilizar, nas linhas 227 e 274, a palavra "brecha" ao invés de "greta", vocábulo mais próximo àquele presente no poema "grieta", justifica Haroldo:

Linha 227: la grieta el resplandor

Linha 274: es la grieta el resplandor el remolino

\author{
la brêche la splendeur \\ est la brêche la splendeur le remous (C. Esteban) \\ the cleft the splendor \\ is the cleft the splendor the whirl (E. Weinberger)
}

Em port., brecha é um termo mais geral que greta (greta: termo de uso mais precisamente técnico, geológico: abertura (brecha) na terra, provocada pelo sol ou pelo tempo de seca). Brecha, em port., pode-se dizer tanto de uma coisa ("uma brecha no muro", "uma brecha no solo", como do corpo humano ("uma brecha na cabeça"). Com som e viabilidade elocutiva, brecha, ao que me parece, resulta melhor em minha língua para transpor a límpida enumeração do seu verso (C. Esteban, em fr., adotou brêche).",

Além das outras traduções, Haroldo consultou também uma primeira versão do poema de Paz e inseriu, em sua transcriação, alguns dos trechos eliminados na segunda versão, sempre no intuito de, com os fragmentos escolhidos e reestruturados, recriar o efeito estético mais pertinente. Segue o diálogo a respeito da solução de Haroldo.

Paz:

Linha 142: ... tierrra, revientas, / tus semillas estallan... // Temor, / terra, desventras, / explodem tuas sementes...

\footnotetext{
${ }^{9}$ PAZ O., CAMPOS, H., 1994, 126.
} 
Suprimi, na versão final, a palavra tremor, mas não me desgosta vê-la reaparecer, pelo menos em português.

Linha: 143: Excelente: Terra, desventras.

Haroldo:

Linhas 142-143: Fiz uma "montagem" das duas variantes do seu texto:

Tremor

Tu panza tiembla

Tus semillas estallan

Verdea la palavra

(cf. Ladera Este; idem,

La Centena / 1935-1968);

e:

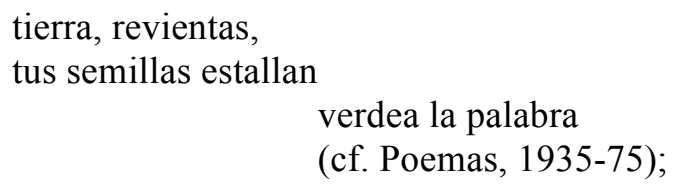

tierra, revientas, tus semillas estallan

verdea la palabra

(cf. Poemas, 1935-75);

donde:

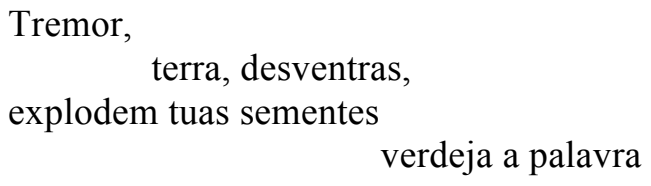

Fico muito contente com a sua aprovação das linhas 142-143 do texto português, que, realmente, ao que me parece, funcionam muito bem em minha língua, uma vez que

\section{TREMor}

Prepara a solução (resolução) fonoprosódica do que segue:

TERRa, desvENTRas, explodEM Tuas seMENTes"10

Benjamin toma a imagem de uma ânfora quebrada para falar sobre a tradução. Os fragmentos não são iguais uns aos outros, assim como a tradução não conseguirá restituir o original a partir do sentido. Apesar disso, os fragmentos são reconhecíveis como partes de uma mesma ânfora, do mesmo modo como, segundo ele, o original e a tradução podem ser identificados com parte de uma língua originária comum (Ursprache). Neste caso, o "modo de dizer" (Art des Meinens), o indizível, é o traço em comum das línguas que, quando recriado em cada uma delas, deixa perceber o rastro de luz - branca - de sua comunicabilidade.

\footnotetext{
${ }^{10}$ Idem, 122, 128, 129.
} 
O poema de Paz, como uma estrutura de mandala, é um círculo, ciclos que se repetem em diferença. O branco, a totalidade, nada mais é do que o pré-início de um ciclo - nascimento, vida e morte, quem diria? - e seu final. Origem e destruição da vida, do poema, da linguagem, do erotismo. Condensação de fragmentos a serem dispersados, condenados a um percurso de existência individual, frágeis cores que escorrem para seu fim / começo.

"Blanco" é também uma alegoria da tradução, onde: o início e o fim, o original e sua tradução, são brancos, mas não são o mesmo: irmãos "siamesmos", estranhos um ao outro; o poema, o processo: a escolha não pela reprodução de uma cor, mas pela recriação do jogo entre ela e suas ausências, os "buracos negros" que a destacam do branco. A vida pulsante da tradução, as diversas vias do poema, múltiplas possibilidades de erros e acertos, combinações de erros e acertos, obra em progresso.

Em mandalas, o fim e o começo, assim como o próprio processo entre ambos, não são estanques e nem se hierarquizam. Nesta formulação, o poema não diz, mas mostra, por seu reluzente modo de apresentação, que a tradução não deve ao original mais do que este deve àquela.

\section{Referências bibliográficas}

BENJAMIN, Walter. A tarefa do tradutor. Cadernos do Mestrado, vol 1. Rio de Janeiro: UERJ, 1992.

CAMPOS, Haroldo. A arte no horizonte do provável. $4^{\mathrm{a}}$ edição. São Paulo: Perspectiva, 1977. (Primeira edição, 1963).

. Metalinguagem e outras metas. São Paulo: Perspectiva, 1992. (Primeira edição, 1967).

PAZ, Octavio. CAMPOS, Haroldo. Transblanco. São Paulo: Editora Siciliano, 1994. (Primeira edição, 1986).

POUND, Ezra. ABC da Literatura. São Paulo: Cultrix, 2001. 